\title{
Effect of addition of buprenorphine or dexamethasone to levobupivacaine on postoperative analgesia in ultrasound guided transversus abdominis plane block in patients undergoing unilateral inguinal hernia repair: a prospective randomized double blind controlled trial
}

\author{
Satya Narayan Seervi ${ }^{1}$, Geeta Singariya ${ }^{1}$, Manoj Kamal $^{2}$, Kamlesh Kumari ${ }^{1}$, \\ Ashwini Siddeshwara ${ }^{1}$, and Shobha Ujwal ${ }^{1}$ \\ Department of Anesthesiology and Critical Care, ${ }^{1} \operatorname{Dr} S \mathrm{~N}$ Medical College, ${ }^{2}$ All India Institute of Medical Sciences, \\ Jodhpur, India
}

\begin{abstract}
Background: The transversus abdominis plane (TAP) block is an effective technique to block the thoracolumbar nerves innervating the anterolateral abdominal wall. This study was conducted to evaluate the analgesic efficacy and opioid consumption with the use of perineural buprenorphine or dexamethasone in TAP blocks after unilateral inguinal hernioplasties.

Methods: This prospective, randomized, double-blinded, placebo-controlled study enrolled 93 patients scheduled for unilateral inguinal hernioplasty, followed by an ultrasound-guided TAP block. The participants were randomized into 3 groups (31 patients each). Group L received $20 \mathrm{ml} \mathrm{0.25 \%} \mathrm{levobupivacaine}+1 \mathrm{ml}$ normal saline (NS); group LB, $20 \mathrm{ml} 0.25 \%$ levobupivacaine + $0.3 \mathrm{mg}$ ( $1 \mathrm{ml}$ ) buprenorphine; and group LD, $20 \mathrm{ml}$ 0.25\% levobupivacaine $+4 \mathrm{mg}(1 \mathrm{ml})$ dexamethasone. The patients were observed postoperatively for $24 \mathrm{~h}$ for first rescue analgesic requirement, total rescue analgesic consumption, and pain scores on the numeric rating scale (NRS).

Results: The time to first rescue analgesic requirement was significantly longer in Group LB than in groups LD and L (688.87 $\pm 36.11 \mathrm{~min}, 601.45 \pm 39.85 \mathrm{~min}$, and $383.06 \pm 36.21 \mathrm{~min}$, respectively; $\mathrm{P}<0.001)$. The mean total tramadol consumption in the first $24 \mathrm{~h}$ was the lowest in group LB $(\mathrm{P}<0.001$, L vs. LB / LD). Groups LB and LD displayed significantly lower NRS scores than group $\mathrm{L}(\mathrm{P}<0.001$ both).

Conclusions: Levobupivacaine with perineural buprenorphine in a TAP block after unilateral open inguinal hernioplasty facilitates prolonged analgesia and reduced requirement for rescue analgesics compared to perineural dexamethasone, without significant side effects.
\end{abstract}

Keywords: Buprenorphine; Dexamethasone; Inguinal hernioplasty; Levobupivacaine; Transversus abdominis plane block.

Corresponding author: Geeta Singariya, M.D.

Department of Anesthesiology and Critical Care, Dr S N Medical College, Shastri Nagar, Jodhpur, Rajasthan 342001, India

Tel: 91-9414803554, Fax: 91-2912434376, Email: geetamanojkamal@gmail.com

ORCID: https://orcid.org/0000-0002-1887-0851

It was presented at 13th ISACON WEST ZONE and 19th ISACON RAJASTHAN, September 2017, All India Institute of Medical Sciences, Jodhpur, India.

Received: June 28, 2018. Revised: July 10, 2018 (1st); October 23, 2018 (2nd). Accepted: January 6, 2019.

Korean J Anesthesiol 2019 June 72(3): 245-252

https://doi.org/10.4097/kja.d.18.00182

(c) This is an open-access article distributed under the terms of the Creative Commons Attribution Non-Commercial License (http://creativecommons.org/ licenses/by-nc/4.0/), which permits unrestricted non-commercial use, distribution, and reproduction in any medium, provided the original work is properly cited. 


\section{Introduction}

Abdominal wall incision is the major contributor to the pain experienced by patients after abdominal surgery. Inguinal hernioplasty is associated with moderate to severe pain that is at its most intense in the initial $24 \mathrm{~h}$ period. Inadequate pain control leads to poor recovery and a prolonged hospital stay and may be a risk factor for persistent pain after surgery. A multimodal approach for post-operative pain management after surgery involving the use of non-steroidal anti-inflammatory drugs, opioids, and local anesthetic infiltration, each acting at different sites of the pain pathway, has been suggested as the optimal combination for pain control [1]. An ultrasonography (USG) guided transversus abdominis plane (TAP) block is an alternative and recent modality, used for postoperative analgesia in inguinal hernioplasty and other lower abdominal surgeries [2]. In a TAP block, a local anesthetic solution is deposited in the plane between the internal oblique (IO) and transversus abdominis (TA) muscles. This blocks the thoracolumbar nerves originating from the T6 to L1 spinal roots that operate in this plane and supply sensation to the parietal peritoneum and the skin and muscles of the anterolateral abdominal wall [3].

In recent times, levobupivacaine is one of the most commonly used local anesthetics with the least cardiotoxic side effects, but its limited duration of analgesia [4] has warranted the addition of various adjuvants to it, aiming at a synergistic enhancement to the quality and duration of analgesia $[5,6]$. Buprenorphine and dexamethasone have been used as adjuvants to local anesthetics in various peripheral nerve blocks $[1,7,8]$, but a search of the available literature did not reveal any study comparing perineural buprenorphine and dexamethasone as adjuvants to levobupivacaine used for post-operative analgesia in a USG-guided TAP block after unilateral open inguinal hernioplasty.

The present study was planned to test the hypothesis that the addition of perineural buprenorphine or dexamethasone as adjuvants to levobupivacaine in a USG-guided TAP block would enhance the duration of post-operative analgesia and reduce opioid consumption in the first $24 \mathrm{~h}$ after unilateral inguinal hernioplasty.

\section{Materials and Methods}

After getting approval from the institutional ethical committee and clinical trial registry of India (CTRI/2017/10/010081) and acquiring written informed consent from the patients, this prospective study was carried out over a period of 6 months from 16 October 2017 to 15 April 2018. Ninety-three patients, 18-60 years old, American society of Anesthesiologist (ASA) physical status I/II, of either sex, scheduled for elective open inguinal hernioplasty with mesh repair under spinal anesthesia were included in the study. The exclusion criteria were patient refusal, known hypersensitivity to local anesthetics, body mass index $\geq 35 \mathrm{~kg} / \mathrm{m}^{2}$, opioid addiction, chronic systemic illnesses, bleeding diathesis, infection at the local site, pregnancy, and failure of the spinal block. The patients were randomized into 3 groups of 31 each by using a computer-generated random number table, and the allotment was done using coded sealed opaque envelopes which were opened just before performing the TAP block. The drug was prepared by Dr KK, the block was performed by Dr GS, and the pain levels were evaluated by Dr S.

During the pre-operative visit detailed patient history was recorded, and a general physical, systemic examination and routine laboratory investigations were conducted. The anesthesia procedure and the numerical rating scale (NRS) for pain were explained to the patients in detail, and they were kept fasting for an $8 \mathrm{~h}$ prior to the surgery. The patients were premedicated with ranitidine $150 \mathrm{mg}$ and alprazolam $0.5 \mathrm{mg}$ orally previous night and on the morning of the surgery.

On arrival in operation theatre, an intravenous (IV) access was established, and standard monitoring in form of electrocardiogram (ECG), pulse oximetry $\left(\mathrm{SpO}_{2}\right)$, and non-invasive blood pressure (NIBP) were applied, and the base line vital parameters were recorded. All patients were hydrated with crystalloid solution $10 \mathrm{ml} / \mathrm{kg}$. Under all aseptic precautions, spinal anesthesia was administered $3 \mathrm{ml}$ of $0.5 \%$ bupivacaine heavy intrathecally in the sitting position at the L3-4 or L4-5 interspace using a 25-G 'Quincke' tip spinal needle (B. Braun Melsungen, Germany). The patients with partial or failed spinal anesthesia were excluded from the study. The ECG and $\mathrm{SpO}_{2}$ were monitored continuously, and NIBP was recorded every 5 min during the intra-operative period.

On completion of the surgical procedure, a USG guided unilateral TAP block was performed under aseptic precautions. After identifying the lower costal margin and iliac crest, the sheathed high frequency linear ultrasound probe $(6-14 \mathrm{MHz}$; Sonosite Bothell, USA) was placed in the mid-axillary line in a transverse plane to obtain a transverse view of the abdominal layers. After the visualization of the abdominal layers, a 22 G 50 $\mathrm{mm}$ blunt insulated nerve block needle was inserted $1 \mathrm{~cm}$ medial to the probe and was advanced using the in-plane technique with real-time USG assessment between the aponeurosis of the IO and the TA muscles [9]. Once the tip of needle was correctly placed, $2 \mathrm{ml}$ normal saline (NS) was injected to hydrodissect the tissue. Following this, the drug was injected in $5 \mathrm{ml}$ increments with gentle intermittent negative aspiration. During the injection, the distribution of the local anesthetic was observed as a hypoechoic enlargement on the USG. Group L received $20 \mathrm{ml} \mathrm{0.25 \%}$ levobupivacaine $+1 \mathrm{ml} \mathrm{NS}$; group LB received 20 $\mathrm{ml} 0.25 \%$ levobupivacaine $+0.3 \mathrm{mg}(1 \mathrm{ml})$ buprenorphine; and 
group LD received $20 \mathrm{ml}$ 0.25\% levobupivacaine $+4 \mathrm{mg}$ (1 ml) dexamethasone, totaling to a $21 \mathrm{ml}$ volume in each group. The anesthesiologist who performed the block was different from the person who assessed the post-operative pain, and both were blinded to the study group.

In the post-operative period, the pain ratings at rest and on movement were measured by NRS ( $0=$ no pain, $10=$ intolerable pain) just after the TAP block and at intervals of 2, 4, 6, 8, 1012 , $15,18,21$, and $24 \mathrm{~h}$. If the pain rating was found to be NRS $>7$ despite the administration of the rescue analgesic at any point of time post-operatively, it implies that the TAP block was not effective. The heart rate, NIBP, and $\mathrm{SpO}_{2}$ were also recorded during this time period. The primary outcomes of the study were the time taken to request for the first analgesic, total rescue analgesic doses in the first $24 \mathrm{~h}$, and the NRS score. Tramadol 2 $\mathrm{mg} / \mathrm{kg}$ IV was administered slowly as the rescue analgesic whenever the NRS $\geq 4$ on rest or on a patient's demand. Tramadol administration was not repeated in $<6$ h. If the NRS was still $>$ 4 , then an additional analgesic injection of paracetamol $1 \mathrm{~g}$ was administered. The patients were evaluated for possible adverse effects including nausea, vomiting, sedation, dry mouth, and headache for $24 \mathrm{~h}$ after the surgery. When a patient felt the urge to vomit, it was labeled as nausea, and when there was a forceful expulsion of gastric contents, as vomiting. Sedation was graded on the Ramsay sedation scale. The patients were also closely monitored for any complications related to the TAP block, such as injection site hematoma and signs of peritoneal infections.

A power analysis was conducted based on previous studies to measure the mean difference in time $(310 \mathrm{~min})$ taken to demand first analgesia in the 2 groups [10,11]. The sample size of $\mathrm{n}=31$ in each group was required for a power of $80 \%$ and significance level of $5 \%$ with a CI of $95 \%$. The a error was 0.05 and $\beta$ error, 0.20 .

Statistical analysis were performed using the IBM Statistical Package for the Social Sciences (SPSS) for windows, version 22.0 (SPSS Inc., USA). Numerical data were analyzed by using an unpaired Students t-test. Categorical data were analyzed by the chi square test or Fisher's exact test as appropriate. The differences among the 3 groups were analyzed by using the one-way analysis of variance (ANOVA) test. The results were expressed as mean \pm standard deviation (SD) or median with interquartile range $(\mathrm{Q} 1, \mathrm{Q} 3)$ or number and percentage (\%). A value of $\mathrm{P}<$
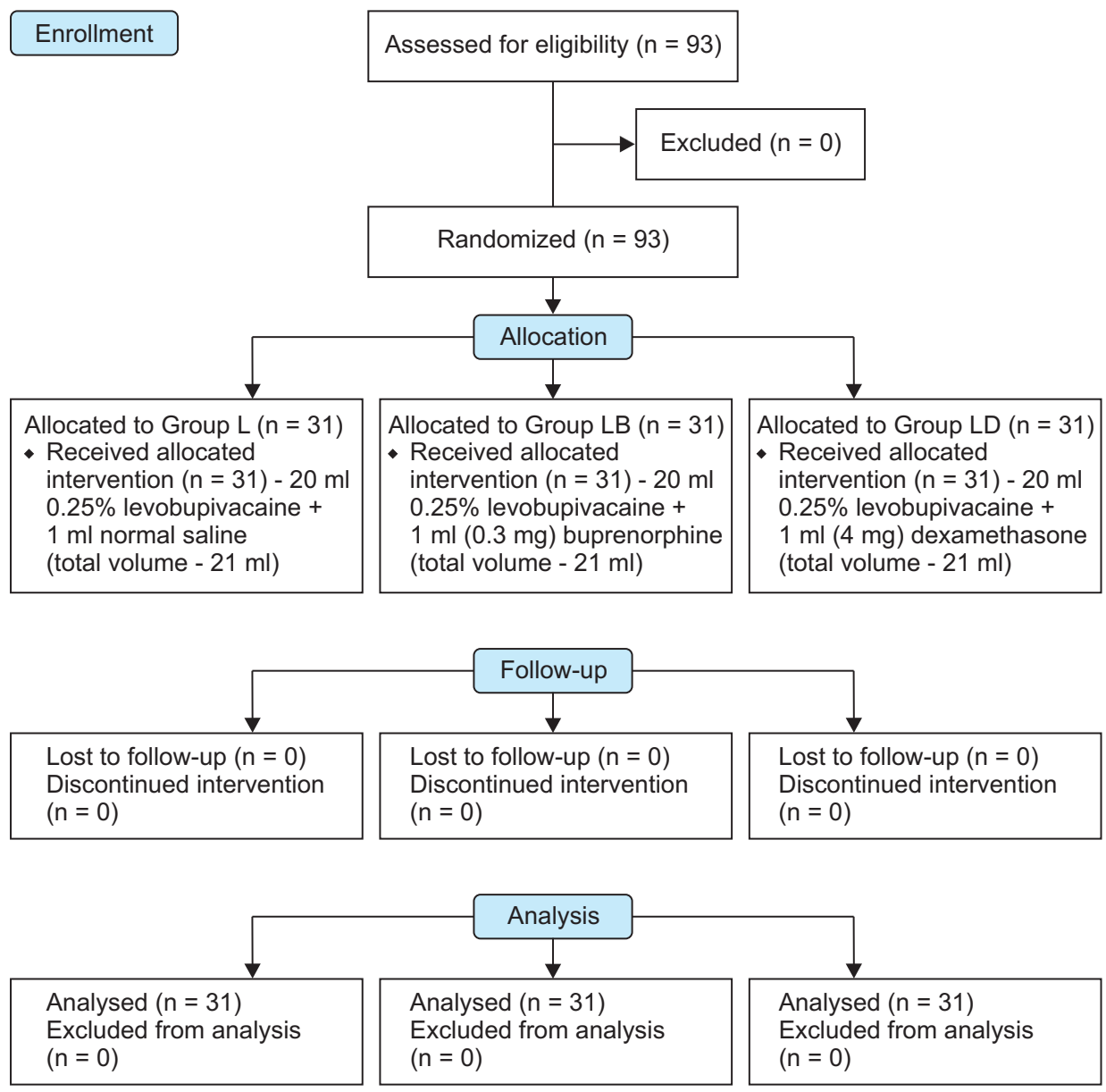

Fig. 1. CONSORT flow diagram. 
0.05 was considered statistically significant.

\section{Results}

A total of 93 patients were recruited for this study. Among all these patients, there were no exclusions or dropouts (Fig. 1). The study groups were comparable in demographic data such as age, weight, ASA-PS and sex (Table 1). The duration of anesthesia was $158.48 \pm 28.08 \mathrm{~min}$ in all 3 groups while the duration of surgery was $51.16 \pm 4.87 \mathrm{~min}$. The hemodynamic and respiratory parameters were comparable among the groups and corresponded to the NRS scores (peak rise in pulse rate and blood pressure).

The mean time to request for first rescue analgesia was the longest in group LB $(688.87 \pm 36.11 \mathrm{~min}, 601.45 \pm 39.85 \mathrm{~min}$, and and $383.06 \pm 36.21 \mathrm{~min}$ for groups $\mathrm{LB}, \mathrm{LD}$, and $\mathrm{L}$, respectively) (Fig. 2). The difference was statistically significant $(\mathrm{P}<$ 0.001 for $\mathrm{L}$ vs. LB/LD and for LB vs. LD) (Table 2). The patients undergoing the TAP block with buprenorphine as an adjuvant had a reduced $24 \mathrm{~h}$ tramadol consumption than those who received dexamethasone as an adjuvant and the control group (158.06 $\pm 50.16 \mathrm{mg}, 177.41 \pm 71.69 \mathrm{mg}$, and $274.19 \pm 44.48 \mathrm{mg}$, respectively. The difference was statistically significant between group L vs. LB and LD $(\mathrm{P}<0.001)$ (Table 2$)$.

The post-operative NRS pain score measured at rest and on movement was reduced in the adjuvant-administered TAP block groups compared to the control group at most but not all the

Table 1. Demographic Characteristic of the Patients

\begin{tabular}{lcccc}
\hline \multicolumn{1}{c}{ Parameters } & Group L & Group LB & Group LD & P value \\
\hline Age $(\mathrm{yr})$ & $43.67 \pm 14.97$ & $40.93 \pm 16.15$ & $42.74 \pm 15.16$ & 0.777 \\
Weight $(\mathrm{kg})$ & $70.51 \pm 4.21$ & $68.80 \pm 3.84$ & $69.90 \pm 4.80$ & 0.275 \\
ASA-PS (I/II) & $15 / 16$ & $16 / 15$ & $16 / 15$ & 0.799 \\
Sex (M/F) & $31 / 0$ & $31 / 0$ & $31 / 0$ & N/A \\
\hline
\end{tabular}

Values are presented as mean \pm SD or number of patients. Group L: 20 $\mathrm{ml} 0.25 \%$ levobupivacaine group $+1 \mathrm{ml} \mathrm{NS}$, Group LB: $20 \mathrm{ml} 0.25 \%$ levobupivacaine $+0.3 \mathrm{mg}(1 \mathrm{ml})$ buprenorphine, Group LD: $20 \mathrm{ml}$ 0.25\% levobupivacaine $+4 \mathrm{mg}(1 \mathrm{ml})$ dexamethasone. ASA-PS: American Society of Anesthesiologists physical status, N/A: not applicable. time points assessed. Mean NRS scores at rest were found to be significantly better in group LB than in groups L and LD from 2 to $12 \mathrm{~h}$ and at $24 \mathrm{~h}$ postoperatively $(\mathrm{P}<0.05)$. Additionally, group LD had a significantly better NRS score at $6 \mathrm{~h}, 10$ to $15 \mathrm{~h}$, and at $24 \mathrm{~h}$ postoperatively compared to group L (Fig. 3A). The mean NRS scores at movement were found to be significantly better in group LB than in groups L and LD from 2 to $10 \mathrm{~h}$ and at $24 \mathrm{~h}(\mathrm{P}<0.05)$. Further, group LD had significantly better NRS scores at $6,10,15$, and 24 h compared to group L (Fig. $3 \mathrm{~B})$. At the end of $10 \mathrm{~h}$ post-surgery the proportion of patients having an NRS $\geq 4$ was the highest in group L (87\%), followed by group LD (81\%) and group LB (36\%). At the end of $24 \mathrm{~h}$ post-surgery, this proportion was still the highest in group $\mathrm{L}$ (90\%), followed by group LD (68\%) and group LB (26\%).

The incidences of nausea, vomiting, dry mouth, and sedation were found to be lower in group LD than in groups L and LB, but the differences were not statistically significant $(\mathrm{P}>0.05)$ (Table 3).

\section{Discussion}

The results of our study demonstrated that the addition of 0.3 $\mathrm{mg}$ buprenorphine or $4 \mathrm{mg}$ dexamethasone to $20 \mathrm{ml}$ levobupiv-

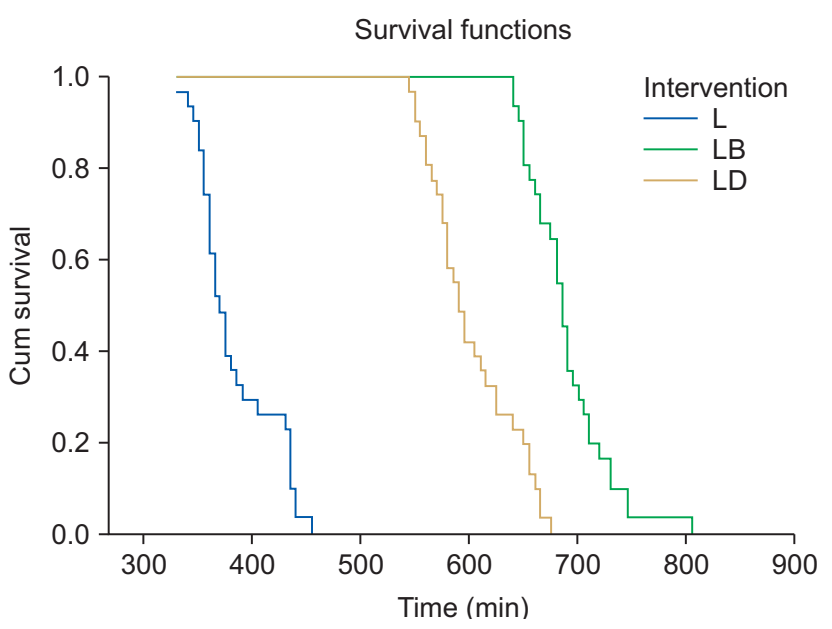

Fig. 2. Kaplan Meier curve of duration of analgesia.

Table 2. Time Taken for the First Analgesia Request and the Total Tramadol Consumption

\begin{tabular}{|c|c|c|c|c|c|c|}
\hline \multirow{2}{*}{ Parameters } & \multirow{2}{*}{ Group L } & \multirow{2}{*}{ Group LB } & \multirow{2}{*}{ Group LD } & \multicolumn{3}{|c|}{ P value } \\
\hline & & & & L vs. LB & L vs. LD & LB vs. LD \\
\hline Duration of analgesia (min) & $\begin{array}{c}370.0(357.5,417.5) \\
383.0 \pm 36.2\end{array}$ & $\begin{array}{c}685.0(662.5,707.5) \\
688.8 \pm 36.1\end{array}$ & $\begin{array}{c}590.0(572.5,632.5) \\
601.4 \pm 39.8\end{array}$ & $<0.001$ & $<0.001$ & $<0.001$ \\
\hline Total tramadol consumption in first $24 \mathrm{~h}(\mathrm{mg})$ & $\begin{array}{r}300.0(200-300) \\
274.1 \pm 44.4\end{array}$ & $\begin{array}{r}200.0(100-200) \\
158.1 \pm 50.1\end{array}$ & $\begin{array}{r}200.0(100-300) \\
177.4 \pm 71.6\end{array}$ & $<0.001$ & $<0.001$ & $>0.050$ \\
\hline
\end{tabular}

Values are presented as Median (interquartile Q1, Q3), Median (range) or mean \pm SD. Group L: $20 \mathrm{ml} 0.25 \%$ levobupivacaine group $+1 \mathrm{ml}$ NS, Group LB: $20 \mathrm{ml}$ 0.25\% levobupivacaine $+0.3 \mathrm{mg}(1 \mathrm{ml})$ buprenorphine, Group LD: $20 \mathrm{ml}$ 0.25\% levobupivacaine $+4 \mathrm{mg}(1 \mathrm{ml})$ dexamethasone. 

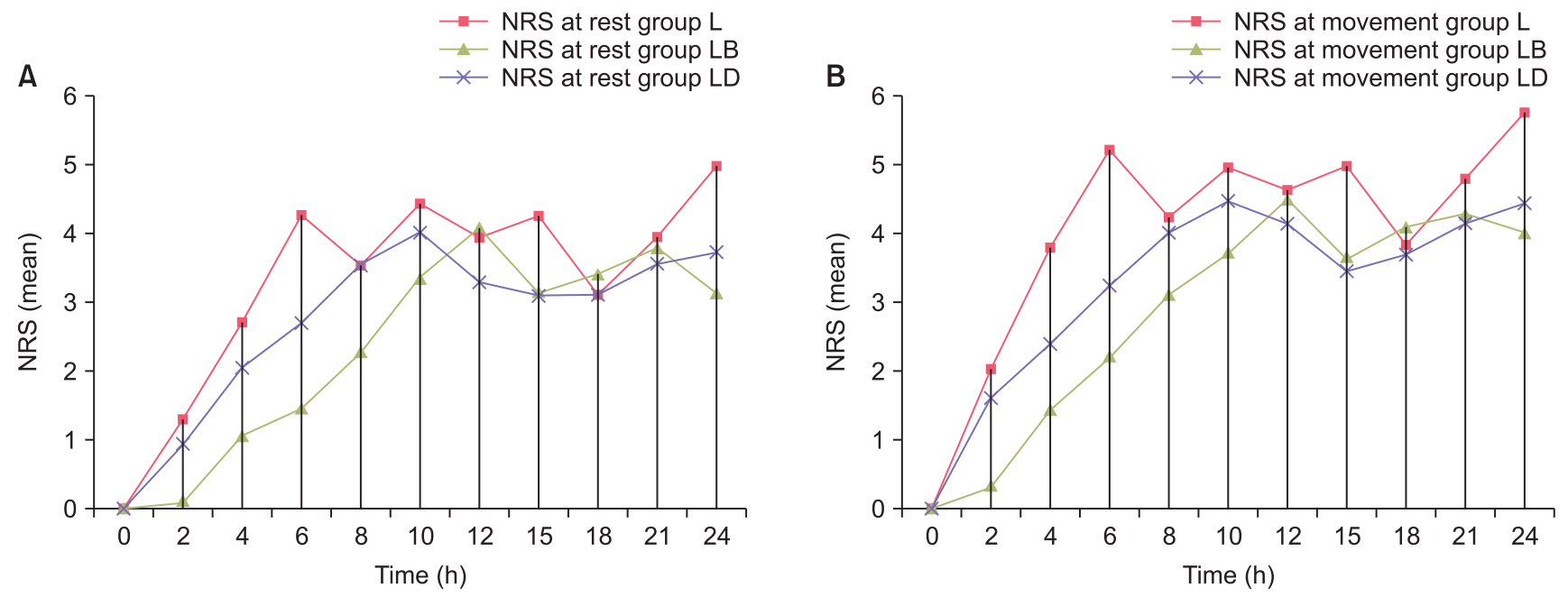

Fig. 3. (A) Comparison of mean numerical rating scale (NRS) score at rest, (B) Comparison of mean NRS score at movement.

Table 3. Incidence of Side Effects

\begin{tabular}{|c|c|c|c|c|c|c|}
\hline \multirow{2}{*}{ Side effect } & \multicolumn{2}{|c|}{$\begin{array}{l}\text { Group L } \\
(\mathrm{n}=31)\end{array}$} & \multicolumn{2}{|c|}{$\begin{array}{l}\text { Group LB } \\
(\mathrm{n}=31)\end{array}$} & \multicolumn{2}{|c|}{$\begin{array}{l}\text { Group LD } \\
(\mathrm{n}=31)\end{array}$} \\
\hline & No. & $\%$ & No. & $\%$ & No. & $\%$ \\
\hline Nausea & 5 & 16 & 4 & 13 & 2 & 6 \\
\hline Vomiting & 2 & 6 & 1 & 3 & 0 & 0 \\
\hline Sedation & 2 & 6 & 1 & 3 & 0 & 0 \\
\hline Headache & 2 & 6 & 1 & 3 & 1 & 3 \\
\hline Dry mouth & 0 & 0 & 2 & 6 & 0 & 0 \\
\hline
\end{tabular}

Values are presented as number of patients or percentage (\%). Group L: $20 \mathrm{ml} \mathrm{0.25 \%}$ levobupivacaine group + $1 \mathrm{ml} \mathrm{NS}$, Group LB: $20 \mathrm{ml}$ 0.25\% levobupivacaine $+0.3 \mathrm{mg}$ ( $1 \mathrm{ml}$ ) buprenorphine, Group LD: $20 \mathrm{ml}$ 0.25\% levobupivacaine $+4 \mathrm{mg}(1 \mathrm{ml})$ dexamethasone.

acaine $0.25 \%$ in a unilateral TAP block provides a prolonged duration of analgesia, reduced opioid consumption, and decreased NRS pain score over a post-operative $24 \mathrm{~h}$ period in patients undergoing unilateral inguinal hernioplasty.

TAP blocks were performed with the help of USG with a higher success rate for post-operative analgesia in inguinal hernioplasty and other lower abdominal surgeries [9,12]. The TAP block is a safe and effective modality for post-operative analgesia as a part of the multimodal approach to analgesia [2,13,14]. A meta-analysis study on the efficacy of a TAP block on post-operative pain reduction demonstrated that it reduces the need for post-operative opioid administration, prolongs the time to the first request of analgesic, provides more effective pain relief, and reduces opioid-associated side effects [15].

The discovery of peripheral opioid receptors led to the clinical application of adding opioids to local anesthetics for peripheral nerve blocks [16]. Due to easy availability, cost effectiveness, lack of significant side-effects like respiratory depression and sedation, longer duration of action [17], highly lipophilic nature, and a high affinity for the $\mu$ receptor, buprenorphine was selected for this study as an adjuvant in the peripheral block. Many studies have evaluated the effect of buprenorphine when added to the local anesthetic for brachial plexus blocks and have concluded that it prolongs post-operative analgesia $[7,18]$, but studies in which buprenorphine was used as an adjuvant with levobupivacaine in a TAP block were not found. According to a study by Kosel et al. [19], $0.3 \mathrm{mg}$ of buprenorphine as an adjuvant with bupivacaine in femoral nerve blocks enhanced the duration of analgesia following total knee arthroplasty. El Sharnouby and El Gendy [20] observed that the addition of 4 $\mathrm{mg}$ dexamethasone was equipotent to $8 \mathrm{mg}$ dexamethasone in a TAP block. Hence, based on the above 2 studies, we used similar doses of adjuvants in our study with levobupivacaine.

Buprenorphine is a partial opioid receptor agonist and blocks voltage-gated $\mathrm{Na}^{+}$channels similar to local-anesthetic agents [21]. It decreases $\mathrm{K}^{+}$ion conduction and increases $\mathrm{Ca}^{2+}$ ion conduction in the cell body of the neurons, which reduces the excitability of the nociceptive neurons and accentuates the prolongation of action potential. Further, it inhibits the release of the excitatory neurotransmitter substance $\mathrm{P}$ from the peripheral sensory nerve endings. The peripheral administration of opioids also has central action due to centripetal movement of opioids binding to opioid binding proteins from the periphery to the dorsal horn [22]. Buprenorphine and its metabolite norbuprenorphine has antihyperalgesic effects attributable to the fact that both have been shown to act on $\kappa$ and $\delta$ opioid receptors in addition to $\mu$ receptors [23].

Behr et al. [24] demonstrated a near doubling of the time to the first analgesic request when perineural buprenorphine was added to levobupivacaine in interscalene blocks for shoulder 
arthroscopy. In another study, Kosel et al. [19] concluded that the use of buprenorphine as an adjuvant to bupivacaine in femoral nerve blockades enhances the quality of the analgesia of the peripheral nerve block and prolongs its duration following primary total knee arthroplasty for up to $48 \mathrm{~h}$ after surgery. Nirmala et al. [11] also found similar results in peritubal blocks for percutaneous nephrolithotomy (PCNL) surgery. Jadon et al. [25] concluded that supraclavicular blocks with bupivacaine and perineural buprenorphine prolonged the duration of analgesia by nearly $6 \mathrm{~h}$ compared to supraclavicular blocks with bupivacaine and intramuscular buprenorphine. Similar results were reported in our study where buprenorphine was found more effective than dexamethasone as an adjuvant to levobupivacaine in terms of a longer duration of analgesia and a lower requirement of rescue analgesia in the post-operative period.

Several studies were carried out to demonstrate the analgesic efficacy and safety of dexamethasone in TAP blocks $[1,10,26]$. Dexamethasone is a long-acting glucocorticosteroid used predominantly for its anti-inflammatory and antiemetic actions. However, its mechanism of action as an adjuvant is not completely understood. A glucocorticoid exhibits anti-inflammatory and analgesic effects through the inhibition of phospholipase A2 and the activation of glucocorticoid receptors. It has been demonstrated that locally administered corticosteroids inhibit signal transmission of nociceptive $\mathrm{C}$-fibers, decrease ectopic neuronal discharge, and decrease the release of local inflammatory mediators [27]. Irrespective of the mechanism of action, all previous studies have recommended the use of dexamethasone to potentiate the analgesia and anesthesia induced by local anesthetic agents administered through various routes $[1,10,26]$.

Ammar and Mahmoud [1] recorded prolonged analgesia when dexamethasone was added to bupivacaine in TAP blocks for abdominal hysterectomies. Studies by Akkaya et al. [10] and Yildiz and Bayir [26] concluded that the addition of dexamethasone as an adjuvant to levobupivacaine in TAP blocks in lower segment cesarean section surgeries provides significantly prolonged, good quality post-operative analgesia, reduced tramadol consumption, and no considerable side effects, such as nausea or vomiting, compared to when dexamethasone is not administered. The results of our study that confirm that dexamethasone added to levobupivacaine provides better analgesia compared to plain levobupivacaine in TAP blocks for unilateral inguinal hernioplasty patients are consistent with the above studies.

The incidence of side effects was comparable among the groups. The incidence of nausea and vomiting was lesser in the dexamethasone group compared to in the buprenorphine group; however, it was not statistically significant because it was mainly attributable to a lower tramadol consumption, but the antiemetic role of dexamethasone cannot be ruled out. Chu et al. [28] have explained the mechanisms of the antiemetic action of dexamethasone. Ammar and Mahmoud [1] have also concluded that the incidence of nausea and vomiting were lower in groups administered with dexamethasone. None of the above-mentioned studies detected a difference in respiratory depression, nausea, or vomiting between those receiving buprenorphine and those receiving a local anesthetic without opioids. However, other studies $[7,8]$ found an increased risk of post-operative nausea and vomiting with the use of perineural buprenorphine.

The limitation of the current study is that the extent of the block under spinal anesthesia could not be assessed which may be important in assessing a successful block. The possibility of systemic changes caused by the study drugs could not be ruled out because we did not check for plasma levels of buprenorphine and dexamethasone. Future studies may be recommended to investigate the systemic effects of these study drugs. Moreover, further large-scale studies may be needed to investigate the extent and efficacy of TAP blocks with different doses and concentrations of levobupivacaine along with different doses of the adjuvants, buprenorphine and dexamethasone. Additionally, it may be studied in different patient populations.

To conclude, the addition of buprenorphine to levobupivacaine in TAP block is more effective regimen to control acute pain following open inguinal hernia repair surgeries as compared to levobupivacaine alone or with addition of dexamethasone.

\section{Conflicts of Interest}

No potential conflict of interest relevant to this article was reported.

\section{Author Contributions}

Satya Narayan Seervi (Data curation; Formal analysis; Writing original draft)

Geeta Singariya (Conceptualization; Methodology; Supervision; Writing - review \& editing)

Manoj Kamal (Writing - review \& editing)

Kamlesh Kumari (Conceptualization; Methodology)

Ashwini Siddeshwara (Data curation; Formal analysis)

Shobha Ujwal (Project administration)

\section{ORCID}

Satya Narayan Seervi, https://orcid.org/0000-0003-4677-1866

Geeta Singariya, https://orcid.org/0000-0002-1887-0851

Manoj Kamal, https://orcid.org/0000-0001-8314-0348

Kamlesh Kumari, https://orcid.org/0000-0003-0652-8802

Ashwini Siddeshwara, https://orcid.org/0000-0003-3877-4311

Shobha Ujwal, https://orcid.org/0000-0002-4190-6381 


\section{References}

1. Ammar AS, Mahmoud KM. Effect of adding dexamethasone to bupivacaine on transversus abdominis plane block for abdominal hysterectomy: A prospective randomized controlled trial. Saudi J Anaesth 2012; 6: 229-33.

2. Abdallah FW, Halpern SH, Margarido CB. Transversus abdominis plane block for postoperative analgesia after Caesarean delivery performed under spinal anaesthesia? A systematic review and meta-analysis. Br J Anaesth 2012; 109: 679-87.

3. Bajwa SJ, Kaur J. Clinical profile of levobupivacaine in regional anesthesia: A systematic review. J Anaesthesiol Clin Pharmacol 2013; 29: 530-9.

4. Saraghi M, Hersh EV. Three newly approved analgesics: an update. Anesth Prog 2013; 60: 178-87.

5. Bonnet F, Berger J, Aveline C. Transversus abdominis plane block: what is its role in postoperative analgesia? Br J Anaesth 2009; 103: 46870.

6. Al-Touny AA, Al-Kassaby AM, Omera MA, Atef HM. The postoperative analgesic efficacy of transversus abdominis plane (TAP) block using bupivacine verus bupivacine-morphine after inguinal herniorrhaphy. Med J Cairo Univ 2013; 81: 1-7.

7. Candido KD, Winnie AP, Ghaleb AH, Fattouh MW, Franco CD. Buprenorphine added to the local anesthetic for axillary brachial plexus block prolongs postoperative analgesia. Reg Anesth Pain Med 2002; 27: 162-7.

8. Candido KD, Hennes J, Gonzalez S, Mikat-Stevens M, Pinzur M, Vasic V, et al. Buprenorphine enhances and prolongs the postoperative analgesic effect of bupivacaine in patients receiving infragluteal sciatic nerve block. Anesthesiology 2010; 113: 1419-26.

9. Venkatraman R, Abhinaya RJ, Sakthivel A, Sivarajan G. Efficacy of ultrasound-guided transversus abdominis plane block for postoperative analgesia in patients undergoing inguinal hernia repair. Local Reg Anesth 2016; 9: 7-12.

10. Akkaya A, Yildiz I, Tekelioglu UY, Demirhan A, Bayir H, Ozlu T, et al. Dexamethasone added to levobupivacaine in ultrasound-guided tranversus abdominis plain block increased the duration of postoperative analgesia after caesarean section: a randomized, double blind, controlled trial. Eur Rev Med Pharmacol Sci 2014; 18: 717-22.

11. Nirmala J, Kumar A, Devraj R, Vidyasagar S, Ramachandraiah G, Murthy PV. Role of buprenorphine in prolonging the duration of post-operative analgesia in percutaneous nephrolithotomy: Comparison between bupivacaine versus bupivacaine and buprenorphine combination. Indian J Urol 2015; 31: 132-5.

12. Yu N, Long X, Lujan-Hernandez JR, Succar J, Xin X, Wang X. Transversus abdominis-plane block versus local anesthetic wound infiltration in lower abdominal surgery: a systematic review and meta-analysis of randomized controlled trials. BMC Anesthesiol 2014; 14: 121.

13. Johns N, O'Neill S, Ventham NT, Barron F, Brady RR, Daniel T. Clinical effectiveness of transversus abdominis plane (TAP) block in abdominal surgery: a systematic review and meta-analysis. Colorectal Dis 2012; 14: e635-42.

14. Weiss E, Jolly C, Dumoulin JL, Meftah RB, Blanié P, Laloë PA, et al. Convulsions in 2 patients after bilateral ultrasound-guided transversus abdominis plane blocks for cesarean analgesia. Reg Anesth Pain Med 2014; 39: 248-51.

15. Siddiqui MR, Sajid MS, Uncles DR, Cheek L, Baig MK. A meta-analysis on the clinical effectiveness of transversus abdominis plane block. J Clin Anesth 2011; 23: 7-14.

16. Picard PR, Tramèr MR, McQuay HJ, Moore RA. Analgesic efficacy of peripheral opioids (all except intra-articular): a qualitative systematic review of randomised controlled trials. Pain 1997; 72: 309-18.

17. Downing JW, Leary WP, White ES. Buprenorphine: a new potent long-acting synthetic analgesic. Comparison with morphine. Br J Anaesth 1977; 49: 251-5.

18. Bazin JE, Massoni C, Bruelle P, Fenies V, Groslier D, Schoeffler P. The addition of opioids to local anaesthetics in brachial plexus block: the comparative effects of morphine, buprenorphine and sufentanil. Anaesthesia 1997; 52: 858-62.

19. Kosel J, Bobik P, Siemiątkowski A. Buprenorphine added to bupivacaine prolongs femoral nerve block duration and improves analgesia in patients undergoing primary total knee arthroplasty-a randomised prospective double-blind study. J Arthroplasty 2015; 30: 320-4.

20. El Sharnouby NM, El Gendy HA. Ultrasound-guided single injection transversus abdominis plane block of isobaric bupivacaine with or without dexamethasone for bariatric patients undergoing laparoscopic vertical banded gastroplasty: a comparative study of different doses. Ain-Shams J Anaesthesiol 2015; 8: 194-9.

21. Leffler A, Frank G, Kistner K, Niedermirtl F, Koppert W, Reeh PW, et al. Local anesthetic-like inhibition of voltage-gated Na(+) channels by the partial $\mu$-opioid receptor agonist buprenorphine. Anesthesiology 2012; 116: 1335-46.

22. Stein C. Peripheral mechanisms of opioid analgesia. Anesth Analg 1993; 76: 182-91.

23. Koppert W, Ihmsen H, Körber N, Wehrfritz A, Sittl R, Schmelz M, et al. Different profiles of buprenorphine-induced analgesia and antihyperalgesia in a human pain model. Pain 2005; 118: 15-22.

24. Behr A, Freo U, Ori C, Westermann B, Alemanno F. Buprenorphine added to levobupivacaine enhances postoperative analgesia of middle interscalene brachial plexus block. J Anesth 2012; 26: 746-51.

25. Jadon A, Panigrahi MR, Parida SS, Chakraborty S, Agrawal PS, Panda A. Buprenorphine improves the efficacy of bupivacaine in nerve plexus block: A double blind randomized evaluation in subclavian perivascular brachial block. J Anaesthesiol Clin Pharmacol 2009; 25: 207-10.

26. Yildiz I, Bayir H. Effect of dexamethasone added to levobupivacaine used for TAP block. Hippokratia 2015; $19: 285$.

27. Johansson A, Hao J, Sjölund B. Local corticosteroid application blocks transmission in normal nociceptive C-fibres. Acta Anaesthesiol 
Scand 1990; 34: 335-8.

28. Chu CC, Hsing CH, Shieh JP, Chien CC, Ho CM, Wang JJ. The cellular mechanisms of the antiemetic action of dexamethasone and related glucocorticoids against vomiting. Eur J Pharmacol 2014; 722: 48-54. 